\title{
A Multi-Objective Marine Predator Optimizer for Optimal Techno-Economic Operation of AC/DC Grids
}

\author{
Mosleh ALHARTHI ${ }^{1}$, Sherif GHONEIM ${ }^{1}$, Abdallah ELSAYED ${ }^{2}$, Ragab EL-SEHIEMY ${ }^{3}$, \\ Abdullah SHAHEEN ${ }^{4 *}$, Ahmed GINIDI ${ }^{4}$ \\ ${ }^{1}$ College of Engineering, Taif University, Taif 21944, Saudi Arabia \\ m.harthi@tu.edu.sa,s.ghoneim@tu.edu.sa \\ ${ }^{2}$ Damietta University, Damietta 22052, Egypt \\ AM.Elsherif@yahoo.com \\ ${ }^{3}$ Kafrelshiekh University, Kafrelshiekh 33516, Egypt \\ elsehiemy@eng.kfs.edu.eg \\ ${ }^{4}$ Suez University, Suez 43518, Egypt \\ abdullahshaheen2015@gmail.com (*Corresponding author), ahmed.ginidi@eng.suezuni.edu.eg
}

\begin{abstract}
This article provides an improved Marine Predator Optimization (IMPO) for the optimized performance of combined alternating/direct current (AC/DC) electrical grids. The optimum performance of such AC/DC electrical grids is approached as a multi-objective issue with the goal of reducing the overall generated environmental emissions, fuel costs and the asSoCiated energy losses. The suggested IMPO includes an exterior repository which is meant to preserve nondominated individuals. The fuzzified decision procedure is often used to employed with a view to determining the correct acceptable operational solution for the combined AC/DC electricity grids. The suggested IMPO is created via the MATLAB environment and is employed on an updated standard power system of standard IEEE 57-bus. Besides, a comparative analysis is performed between the proposed IMPO algorithm, particle swarm optimization, bat optimization, dragonfly optimization, crow search optimization, grey wolf optimization, multi-verse optimization and salp swarm optimization. The simulation outputs demonstrate the effectiveness and preponderance of the proposed IMPO with capability in extracting well-diversified Pareto solutions.
\end{abstract}

Keywords: Marine predator optimizer, Multi-objective, AC/DC networks, Optimal management, Losses.

\section{Introduction}

The techno-economic operation of power systems is a high-level, non-linear, multi-dimensional, and controlled optimization issue. The optimal power flow (OPF) is as a pivotal tool for Grid System Operators (GSO) (Secui et al., 2014). The optimal operating point of a power system is determined by the $(\mathrm{OPF})$ calculations with respect to single and multiple-objective functions (economical, technical, or environmental) which are exposed to grid and diverse operation constraints (E1Sehiemy, El-Hosseini \& Hassanien, 2013). The objective functions of OPF are considered, while keeping the diverse equality and inequality constraints, to reduce generation costs, reduce environmental emissions, reduce transmission losses, increase system loadability, improve voltage performance, system reliability, security (Mohagheghi et al., 2018) and for profit enhancement for generating companies.

Worldwide, a plethora of Voltage Source Converters (VSCs) are installed with High Voltage Direct Current (HVDC) to transmit great amounts of power through undersea/ underground cables or over long distances. The VSC-HVDC transmission systems have lots of merits such as black-start capability, decoupled control of active and reactive power, and lower footprint. Currently, using Modular Multilevel Converters, those links are assembled with point-to-point connections. However, the system is modified to a Multi-Terminal HVDC (MTHVDC) system to achieve flexibility when using more terminals of the existing links. Moreover, with adding more paths to the MT system, it is exchanged into a meshed HVDC grid. This modified system can achieve redundancy and further flexibility for the transmission system and integration of diverse renewable resources. To illustrate this, the first meshed HVDC grid has been executed in the Chinese project named Zhang-Bei to deliver renewable supply for Beijing with 4 terminals in a ring connection and 2 terminals in the first and second phase, respectively (Sau-Bassols et al., 2019).

The conventional operation power systems' methodologies, such as state estimation (Donde et al., 2016), the economic dispatch (Hamad \& El-Saadany, 2016), and optimal power flow (Li et al., 2019)stand-alone DC-MG has many distinct applications. However, the optimal power flow problem (OPF, are required to be 
adapted the integrated MTHVDC grids. When applied to integrated AC/MTHVDC systems, the OPF becomes a non-linear, complex, and nonconvex issue, because it contains a large number of optimization variables and system constraints (Sayah, 2018).

Currently, the OPF mathematical formulation for AC-MTHVDC grids enjoy great consideration in literature. In this regard, in (Hotz et al., 2020), a unified representation of $\mathrm{AC}$ and $\mathrm{DC}$ sub-grids and flexible converter model are introduced. The influence of Voltage Source Converter (VSC) losses on the solution of the OPF of hybrid AC/ DC systems is analyzed in (Zhao \& Echavarren, 2017) with a multi-terminal configuration. With/ without renewable penetration, several objectives of OPF of AC grids are analyzed in (Shafik et al., 2019). The OPF of DC grids only is presented are in (Duan et al., 2018)(Mackay, Member \& Guarnotta, 2018). Under load and generation uncertainties, the OPF strategy is illustrated in an AC-DC hybrid microgrid (Maulik \& Das, 2019). A simplified algorithm is implemented in (Renedo, et al., 2019) on (OPF) in hybrid VSC-based (AC/ DC) grids with VSC-MTHVDC systems.

One of the recent optimizers is the Marine Predators Optimizer (MPO) (Faramarzi et al., 2020). The strategies of this optimizer for surviving depend on Lévy, Brownian movements and the iterations are separated into three dispersed portions. This article proposes an improved version of MPO (IMPO). This IMPO illustrates a combination between the predator's strategies and the occurrence of environmentally random circumstances. Additionally, the IMPO is proposed to handle multi-objective issues simultaneously. The proposed IMMPO advocates an external archive with a specific volume. Besides, the non-dominated preys are well-maintained in this archive, whereas Pareto dominance is stimulated to discriminate between the old and new preys. Yet, in each iteration, the top predator is extracted, randomly, from the least overfilled zone in the archive. Furthermore, the proposed IMMPO is employed on an updated IEEE 57-bus grid to get the optimal solution to the mentioned issue in AC/MTHVDC Grids. A comparison with regard to these applications is illustrated between the proposed optimizer and diverse recent optimizers such as: crow search optimization algorithm (CSOA) (Shaheen \& El-Sehiemy, 2017) (Shaheen, 2021a), Particle swarm optimizer (PSO) and salp swarm optimization (SSA) (Shaheen \& El-Sehiemy, 2020a), grey wolf optimizer (GWO) (Shaheen \& El-Sehiemy, 2020b), Bat optimizer (BAT) (Meng et al., 2015), dragonfly algorithm (DA) (Mirjalili, 2016), and multi-verse optimizer (MVO) (Shaheen, 2019). Although the use of Levi flights has been incorporated with BAT optimizer (Enache, Sgarciu \& Petrescu-Nita, 2015) but its modification was dedicated to a binary version.

This paper is organized as follows. Section 2 presents the OPF formulation in AC-MTHVDC grids. The proposed IMMPO is detailed in Section 3 . Then, the simulation outcomes are presented and analysed in Section 4. Section 5 outlines the conclusions of this paper.

\section{Problem Formulation}

\section{Objective Functions}

\section{A) Fuel generation costs $\left(F_{1}\right)$}

This objective function is modelled as a quadratic function and can be depicted as:

$\mathrm{F}_{1}=\sum_{\mathrm{i}=1}^{\mathrm{N}_{\mathrm{g}}} \mathrm{a}_{\mathrm{i}} \mathrm{Pg}_{\mathrm{i}}^{2}+\mathrm{b}_{\mathrm{i}} \mathrm{Pg}_{\mathrm{i}}+\mathrm{c}_{\mathrm{i}}$

\section{B) AC-MTCDC grids Total Power losses $\left(\mathrm{F}_{2}\right)$}

This objective represents the summation of AC grid line losses, DC transmission losses, and VSC stations loss and can be modelled as it is depicted in equation (2). However, DC and AC losses are manifested as illustrated via equations (3) and (4). Furthermore, the VSC losses can be represented as a converter current $\left(\mathrm{Ic}_{\mathrm{i}}\right)$ quadratic function which is relevant to each VSC.

$$
\begin{aligned}
& \mathrm{F}_{2}=\mathrm{AC}_{\text {loss }}+\mathrm{DC}_{\text {loss }}+\mathrm{VSC}_{\text {loss }} \\
& \mathrm{DC}_{\text {loss }}=\sum_{\mathrm{i}, \mathrm{j} \in \mathrm{N}_{\mathrm{DC}, \mathrm{b}}} \mathrm{R}_{\mathrm{ijj}} \mathrm{I}_{\mathrm{ij}}^{2} \\
& \mathrm{AC}_{\text {loss }}=\sum_{\mathrm{i}, \mathrm{j} \in \mathrm{N}_{\mathrm{A} C \mathrm{~b}}} \mathrm{G}_{\mathrm{ij}}\left(\mathrm{V}_{\mathrm{i}}^{2}+\mathrm{V}_{\mathrm{j}}^{2}-2 \mathrm{~V}_{\mathrm{i}} \mathrm{V}_{\mathrm{j}} \cos , \mathrm{ij}\right) \\
& \mathrm{VSC}_{\text {loss }}=\sum_{\mathrm{i}=1}^{\mathrm{N}_{\text {vsS }}} \varphi_{1, \mathrm{i}} \mathrm{I}_{\mathrm{c}, \mathrm{i}}{ }^{2}+\varphi_{2, \mathrm{i}} \mathrm{I}_{\mathrm{c}, \mathrm{i}}+\varphi_{3, \mathrm{i}}
\end{aligned}
$$

https://www.sic.ici.ro 
where $\mathrm{V}_{\mathrm{i}}$ and $\mathrm{V}_{\mathrm{j}}$ are the voltages at buses $\mathrm{i}$ and $\mathrm{j}$. $R_{\mathrm{ij}}, I_{\mathrm{ij}}$, and $\theta_{\mathrm{ij}}$ are the resistance, current flow and phase differences between buses $i$ and $j$. Nvsc is the number of VSC devices.

\section{Control and Dependent Variables of AC-MTHVDC Grids}

The 'coupling relationship' in this grid is implemented among the control devices of both the HVDC and AC power systems. To illustrate this dilemma, generators' voltage and power output, VAR injection sources, and transformer tap settings are the main pillars of conventional controls of the AC grids (Warid, 2020)an adaptive multiple teams perturbation-guiding Jaya (AMTPG-Jaya. However, four control strategies are developed for the advanced control of the VSC (Shaheen and El-Sehiemy, 2020a) which are (Vdc/ $\mathrm{Vc})$ constant control, $(\mathrm{Vdc} / \mathrm{Qc})$ constant control, control, (Pdc/Vc) constant control, and (Pdc/ Qc) constant control. The dependent variables can be categorized according to MTHVDC side and $\mathrm{AC}$ side. To manifest, the power flow though the DC lines and the DC bus voltage represents the dependent variables of the MTHVDC side, whereas transmission line loadings (SF), generator reactive power outputs $\left(\mathrm{Q}_{\mathrm{g}}\right)$, and the load bus voltage magnitudes (VL) characterize the AC grids dependent variables $\left(\mathrm{y}_{\mathrm{AC}}\right)$ which can be modelled as it can be seen in equation (6) (Li et al., 2019).

$$
\mathrm{y}_{\mathrm{AC}}=\left[\mathrm{VL}_{1} \ldots . \mathrm{VL}_{\mathrm{NPQ}}, \mathrm{Qg}_{1} \ldots \mathrm{Qg}_{\mathrm{Ng}}, \mathrm{SF}_{1} \ldots . \mathrm{SF}_{\mathrm{NF}}\right]
$$

\section{Constraints}

\section{A) Equality constraints}

The AC grid load flow balance equations are mathematically illustrated as denoted in equations $(7,8)$ (Shaheen \& El-Sehiemy, 2020a) (Warid, 2020):

$$
\begin{aligned}
& \mathrm{Qg}_{\mathrm{i}}-\mathrm{QL}_{\mathrm{i}}+\mathrm{Qc}_{\mathrm{i}}-\mathrm{V}_{\mathrm{i}} \sum_{\mathrm{j}=1}^{N_{\mathrm{b}}} \mathrm{V}_{\mathrm{j}}\left(G_{\mathrm{ij}} \sin _{, \mathrm{ij}}-\mathrm{B}_{\mathrm{ij}} \cos , \mathrm{ij}\right)=0, \mathrm{i}=1,2, \ldots \mathrm{NPQ} \\
& \mathrm{Pg}_{\mathrm{i}}-\mathrm{PL}_{\mathrm{i}}-\mathrm{V}_{\mathrm{i}} \sum_{\mathrm{j}=1}^{N_{\mathrm{k}}} \mathrm{V}_{\mathrm{j}}\left(\mathrm{G}_{\mathrm{ij}} \cos ,{ }_{, \mathrm{ij}}+\mathrm{B}_{\mathrm{ij}} \sin , \mathrm{ij}\right)=0, \mathrm{i}=1, \ldots \mathrm{N}_{\mathrm{b}} \text {-slack }
\end{aligned}
$$

However, the constraints of DC grid power flow are elaborated as:

$$
P_{d c, i}=V_{d c, i} \sum_{\substack{i=1 \\ i \neq j}}^{N_{v s c}} G_{d c, i j}\left(V_{d c, i}-V_{d c, j}\right)
$$

where, $\mathrm{V}_{\mathrm{dc}, \mathrm{i}}$ and $\mathrm{V}_{\mathrm{dc}, \mathrm{j}}$ is the DC voltage at buses $\mathrm{i}$ and j. Furthermore, $\mathrm{AC}$ grids' variables have to be maintained according to the following constraints (Shaheen \& El-Sehiemy, 2020a) (Li et al., 2019):

$$
\begin{aligned}
& \mathrm{Vg}_{\mathrm{i}}^{\min } \leq \mathrm{Vg}_{\mathrm{i}} \leq \mathrm{Vg}_{\mathrm{i}}^{\max }, \mathrm{i}=1,2, \ldots \ldots \mathrm{Ng} \\
& \mathrm{Pg}_{\mathrm{i}}^{\min } \leq \mathrm{Pg}_{\mathrm{i}} \leq \mathrm{Pg}_{\mathrm{i}}^{\max }, \mathrm{i}=1,2, \ldots \ldots \mathrm{Ng} \\
& \mathrm{Qg}_{\mathrm{i}}^{\min } \leq \mathrm{Qg}_{\mathrm{i}} \leq \mathrm{Qg}_{\mathrm{i}}^{\max }, \mathrm{i}=1,2, \ldots \ldots \mathrm{Ng} \\
& \mathrm{Qc}_{\mathrm{q}}^{\max } \leq \mathrm{Qc}_{\mathrm{q}} \leq \mathrm{Qc}_{\mathrm{q}}^{\max }, \mathrm{q}=1,2, \ldots \ldots \mathrm{Nq} \\
& \mathrm{Tap}_{\mathrm{k}}^{\min } \leq \mathrm{Tap}_{\mathrm{k}} \leq \mathrm{Tap}_{\mathrm{k}}^{\max }, \mathrm{k}=1,2, \ldots \ldots \mathrm{Nt} \\
& \mid \mathrm{S}_{\mathrm{F}}{ } \leq \mathrm{S}_{\mathrm{F}}^{\max }, \mathrm{L}=1,2, \ldots \ldots \mathrm{Nf} \\
& \mathrm{V}_{\mathrm{L}_{\mathrm{i}}}^{\min } \leq \mathrm{V}_{\mathrm{L}_{\mathrm{i}}} \leq \mathrm{V}_{\mathrm{L}_{\mathrm{i}}}^{\max }, \mathrm{i}=1,2, \ldots \ldots \mathrm{NPQ}
\end{aligned}
$$

where $\mathrm{Q}_{\mathrm{gi}}$ is the reactive output from generator $\mathrm{g} ; \mathrm{Q}_{\mathrm{cq}}$ is the reactive output from compensator q; Tap $_{\mathrm{k}}$ is the tap value of transformer $\mathrm{k}$; $\mathrm{S}_{\mathrm{F}}$ is the power flow, $\mathrm{V}_{\mathrm{Li}}$ is the load voltage at bus $\mathrm{i}$.

\section{B) Inequality constraints}

In the same way, the MTHVDC grid has inequality constraints as illustrated in the following equations (Li et al., 2019):

$$
\begin{aligned}
& \mathrm{Vc}_{i}^{\min } \leq \mathrm{Vc}_{\mathrm{i}} \leq \mathrm{Vc}_{\mathrm{i}}^{\max }, \mathrm{i}=1,2, \ldots \ldots \mathrm{N}_{\mathrm{VSC}} \\
& \mathrm{V}_{\mathrm{dcci}}^{\min } \leq \mathrm{V}_{\mathrm{dcci}} \leq \mathrm{V}_{\mathrm{dcci}}^{\max }, \mathrm{i}=1,2, \ldots \ldots \mathrm{N}_{\mathrm{DC}} \\
& \mathrm{Ps}_{\mathrm{i}}^{\min } \leq \mathrm{Ps}_{\mathrm{i}} \leq \mathrm{Ps}_{\mathrm{i}}^{\max }, \mathrm{i}=1,2, \ldots \ldots \mathrm{N}_{\mathrm{VSC}} \\
& \mathrm{Qs}_{\mathrm{i}}^{\min } \leq \mathrm{Qs}_{\mathrm{i}} \leq \mathrm{Qs}_{\mathrm{i}}^{\max }, \mathrm{i}=1,2, \ldots \ldots \mathrm{N}_{\mathrm{VSC}}
\end{aligned}
$$

where $\mathrm{V}_{\mathrm{ci}}$ is the converter voltage at bus $\mathrm{i}$ where $\mathrm{Ps}_{\mathrm{i}}$ and $\mathrm{Qs}_{\mathrm{i}}$ are the active power output and reactive power outputs at the AC side at bus i, respectively. Besides, the PQ capability curve for each VSC must be maintained as:

$$
\mathrm{d}_{\mathrm{i}}^{\min } / 2 \leq \sqrt{\left(\mathrm{Ps}_{\mathrm{i}}-\mathrm{P}_{\mathrm{o}}\right)^{2}-\left(\mathrm{Qs}_{\mathrm{i}}-\mathrm{Q}_{\mathrm{o}}\right)^{2}} \leq \mathrm{d}_{\mathrm{i}}^{\max } / 2, \mathrm{i}=1,2, \ldots, \mathrm{N}_{\mathrm{DC}}
$$

where $\left(P_{0}, Q_{0}\right)$ represents the centre of the circles which is relevant to the VSC PQ-capability, while $\mathrm{d}$ indicates its diameter.

\section{Techno-economic Operation of AC/DC Grids with IMPO}

The MPO initializes with random prey's positions (Y) and their number is represented by $\mathrm{P}_{\text {Size }}$. Moreover, with $\mathrm{P}_{\text {Size }}$ the population, the top predator represents the fittest solution, and they are copied in an Elite (E) matrix. Three sequential stages are developed for catching the prey in MPO and they form the searching journey. In the first stage "reconnoitring", the predator runs with very low speed with respect to the prey movement because it performs a military observation for the surrounding district. 
Moving to the second stage, the predators are still searching for the target or may select the wanted prey and this stage represents a balance between the reconnoitring and chasing. Hence, the relative speed between the prey and the predator is approximately the same. In this stage, the population size is divided likewise such that preys are responsible for discovery, while predator individuals are responsible for exploitation. The third stage is hunting process, where the predator moves quicker than prey's target, which depicts the predators' skills in finding the targeted prey. These stages are mathematically represented to change the location $\left(\mathrm{X}^{*}\right)$ related to every prey (i) as in equation (22) as follows:

$\vec{X}_{i}^{*}= \begin{cases}\vec{X}_{i}+0.5 \vec{R} \otimes \vec{R}_{m} \otimes\left(\vec{E}_{i}-\vec{R}_{m} \otimes \vec{X}_{i}\right) & \text { if It } \leq \frac{\text { Maxit }}{3} \\ \vec{E}_{i}+0.5 C_{I t} \otimes \vec{R}_{n} \otimes\left(\vec{R}_{n} \otimes \vec{E}_{i}-\vec{X}_{i}\right) & \text { if } \quad \text { It } \geq \frac{2 \text { Maxit }}{3} \\ \vec{X}_{i}+0.5 \vec{R} \otimes \vec{R}_{n} \otimes\left(\vec{E}_{i}-\vec{R}_{n} \otimes \vec{X}_{i}\right) & \text { else \& if } i \leq \frac{P_{S}}{2} \\ \vec{E}_{i}+0.5 C_{1 t} \otimes \vec{R}_{m} \otimes\left(\vec{R}_{m} \otimes \vec{E}_{i}-\vec{X}_{i}\right) & \text { else \& if } i>\frac{P_{S}}{2}\end{cases}$

where $\mathrm{R}$ represents a vector in the range $[0,1]$. Moreover, the symbol $\otimes$ illustrates Hadamard product, whilst $R_{m}$ represents a random vector which depends on Gaussian distribution, which displays the random fluctuations-based Brown concept. Besides, $R_{n}$ indicates a random vector which depends on Lévy motion. The symbol $\left(\mathrm{C}_{\mathrm{It}}\right)$ implies a dynamic parameter employed for managing the predator's navigation and is adaptively varied with iteration progress which can be mathematically modelled as:

$\mathrm{C}_{\mathrm{It}}=\left(1-\frac{\mathrm{It}}{\text { Maxit }}\right)^{\left(\frac{2 \mathrm{lt}}{\text { Maxit }}\right)}$

Beside the previous strategies, the Fish Aggregating $\left(\mathrm{F}_{\mathrm{A}}\right)$ influences have been adopted, where the updating strategy can be expressed as:

$\vec{X}_{i}^{*}=\left\{\begin{array}{cc}\vec{X}_{i}+C_{I t}\left(\vec{X}_{\text {min }}+\vec{R} \otimes\left(\vec{X}_{\text {max }}-\vec{X}_{\text {min }}\right) \otimes \vec{U}\right. & \text { if } \mathrm{r}_{1} \leq \mathrm{F}_{\mathrm{A}} \\ \overrightarrow{\mathrm{X}}_{\mathrm{i}}+\left(\overrightarrow{\mathrm{X}}_{\mathrm{x}}-\overrightarrow{\mathrm{X}}_{\mathrm{y}}\right) \cdot\left(\mathrm{F}_{\mathrm{A}}\left(1-\mathrm{r}_{1}\right)+\mathrm{r}_{1}\right) & \text { else }\end{array}\right.$ where $X_{\max }$ and $X_{\min }$ are relevant to the limits of the decision variables. Moreover, $\mathrm{F}_{\mathrm{A}}$ signifies the probability coefficient which is relevant to the influence of fish aggregation. When updating the preys' positions, every fitness (Fit) is estimated, and consequently, Elite (E) matrix is modified as it is expressed in equation (25) as:

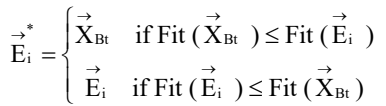

where $\mathrm{E}^{*}$ represents the updated position matrix of predators, whereas $\mathrm{X}_{\mathrm{Bt}}$ characterizes the preys' best location which attains the minimum fitness (Shaheen, 2021b).

\section{Proposed IMPO for Optimal Management of AC/DC Electrical Grids}

The idea of IMPO was generated because the preys, in certain cases, become disoriented when on their way to the predators or that some preys are brilliant to hide themselves. Accordingly, the iterative variations are broken to 3 divided dispersed and sequential pillars which cancel the occurrence of these circumstances. This can be represented by adding random possibilities of combining these stages as it is shown in equation (26) below. To solve the multiobjective framework, an IMMPO is proposed to integrate an exterior repository in predetermined amount. Depending on Pareto dominance, the non-dominated preys are stored and changed twice in every iteration. An erasing process is performed, if this repository is full in order to delete a few of the Pareto individuals, using the roulette wheel option, in the most overfilled zones (Renedo et al., 2019). On the other hand, the roulette wheel is used to increase the odds of selecting a representative solution among the least congested areas. In each iteration, the updated procedure of the prey's locations is

$$
\vec{X}_{i}^{*}=\left\{\begin{array}{l}
\vec{X}_{i}+0.5 \vec{R} \otimes \vec{R}_{m} \otimes\left(\vec{E}_{i}-\vec{R}_{m} \otimes \vec{X}_{i}\right) \text { if It } \leq \frac{\text { Maxit }}{3} \& \text { if rand } \leq \text { rand } \\
\vec{X}_{i}+0.5 \vec{R} \otimes \vec{R}_{n} \otimes\left(\vec{E}_{i}-\vec{R}_{n} \otimes \vec{X}_{i}\right) \quad \text { if } \frac{\text { Maxit }}{3}<\text { It } \leq \frac{2 \text { Maxit }}{3} \& \text { if } i \leq \frac{P_{S}}{2} \& \text { if rand } \leq \text { rand } \\
\vec{E}_{i}+0.5 C_{I t} \otimes \vec{R}_{m} \otimes\left(\vec{R}_{m} \otimes \vec{E}_{i}-\vec{X}_{i}\right) \text { if } \frac{\text { Maxit }}{3}<\text { It } \leq \frac{2 \text { Maxit }}{3} \& \text { if } i>\frac{P_{S}}{2} \& \text { if rand } \leq \text { rand } \\
\vec{E}_{i}+0.5 C_{I t} \otimes \vec{R}_{n} \otimes\left(\vec{R}_{n} \otimes \vec{E}_{i}-\vec{X}_{i}\right) \text { else }
\end{array}\right.
$$

https://www.sic.ici.ro 
created as it is expressed in equation (26) based on the dominance priority.

Besides, the non-dominated preys are wellmaintained in this archive, whereas Pareto dominance is stimulated to differentiate between the old and new preys. Yet, in each iteration, the top predator is extracted, randomly via roulette wheel selection, from the least overfilled zone in the archive.

$\overrightarrow{\mathrm{X}}_{\mathrm{i}, \mathrm{It}+\mathrm{l}}=\left\{\begin{array}{l}\overrightarrow{\mathrm{X}}_{\mathrm{i}}^{*} \text { if } \overrightarrow{\mathrm{X}}_{\mathrm{i}} \text { dominates } \overrightarrow{\mathrm{X}}_{\mathrm{i}}^{*} \\ \overrightarrow{\mathrm{X}}_{\mathrm{i}} \quad \text { if } \overrightarrow{\mathrm{X}}_{\mathrm{i}} \text { doesnot dominate } \overrightarrow{\mathrm{X}}_{\mathrm{i}}^{*}\end{array}\right.$

Hence, in preceding iteration, every new location is contrasted with its prior accomplished objectives. A Pareto set is created and maintained, to preserve the diversity and enriches the solution quality. A fuzzified decision tool (Shaheen \& El-Sehiemy, 2020b) is applied to extract the conciliation operational solution. The flowchart of the proposed IMPO is illustrated in Figure 1 to enable AC-HVDC power systems optimal operation.

\section{Simulation Results}

The proposed IMPO is applied for the modified IEEE 57-bus network (Figure 2) as a combined AC/DC electrical grid. To evaluate the effectiveness of the proposed IMPO, various recent algorithms are employed for the same target such as (CSOA) (Shaheen \& El-Sehiemy, 2017), Particle swarm optimization (PSO) and salp swarm optimization (SSA) (Shaheen \& ElSehiemy, 2020a), grey wolf optimizer (GWO) (Shaheen \& El-Sehiemy, 2020b), Bat algorithm (BAT) (Sambariya \& Prasad, 2014), dragonfly algorithm (DA) (Mirjalili, 2016), and multiverse optimizer (MVO) (Shaheen, 2019). The compared algorithms have the same number of fitness evaluations (15000), whereas 300 iterations are set as the maximum. They are performed ten times each. The IEEE 57-bus system originally has 57 buses, 80 lines, 8 generators, 17 on-load tap changing transformers and 3 shunt capacitive sources.

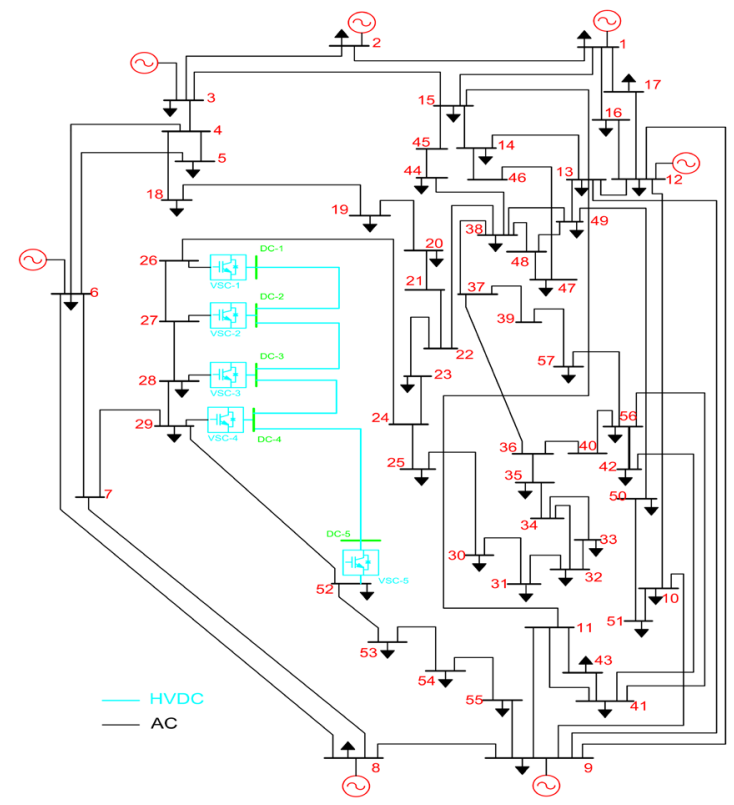

Figure 2. Modified IEEE 57-bus system

The complete data is taken from (Shaheen, ElSehiemy \& Farrag, 2019). Its maximum and minimum values for the generator and load voltage are 1.06 and 0.94 p.u., respectively. The reactive compensation is limited by 30 MVAr. This system is modified with five VSCs and four DC connected lines. The VSCs are located at bus 26-29 and 52, respectively (Shaheen, 2021c).

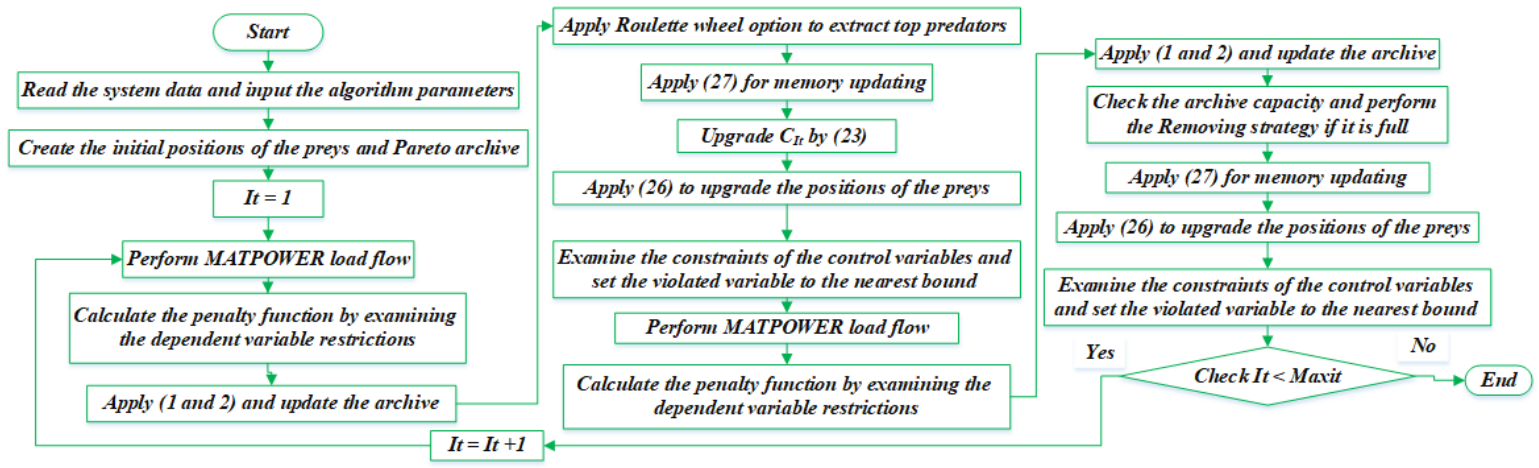

Figure 1. Proposed IMPO for handling the considered problem (Elsayed et. al, 2021) 


\section{Case 1: Fuel Costs Minimization}

Table 1 reports the optimal control variables and the corresponding technical and economic objectives in Case 1. The proposed IMPO and other techniques (CSOA, PSO, SSA, GWO, BAT, DA, MVO, and standard MPO). From the obtained results the proposed IMPO can minimize the total fuel cost from $53673.15 \$ / \mathrm{h}$ to 41920.67 $\$ / \mathrm{h}$ with a reduction of $21.89 \%$.

Figures 3 and 4 show the voltage profile of $\mathrm{AC}$ and DC grid, respectively, for the initial case, MPO and IMPO. From Figure 3, the lowest voltage is $92 \%$ at bus 30 and $92.5 \%$ at bus 57 based on MPO and IMPO, respectively whereas the highest voltage is $107.1 \%$ at bus 25 and $106 \%$ at bus 8 based on MPO and IMPO, respectively. For the DC grid, Figure 4 derives the same remarks where the lowest voltage is $106.7 \%$ and $108 \%$ at bus 1 based on MPO and IMPO, respectively whereas the highest voltage is $109.71 \%$ and $109.68 \%$ at bus 5 based on MPO and IMPO, respectively. Those figures state the fulfilment of the voltage constraints for $\mathrm{AC} / \mathrm{DC}$ power grid whereas the voltages of all buses are within the allowable limits.

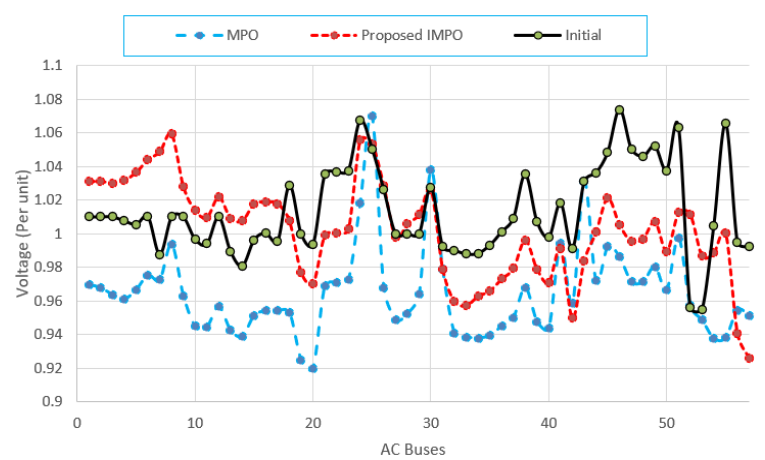

Figure 3. Voltages of AC grid for fuel cost minization

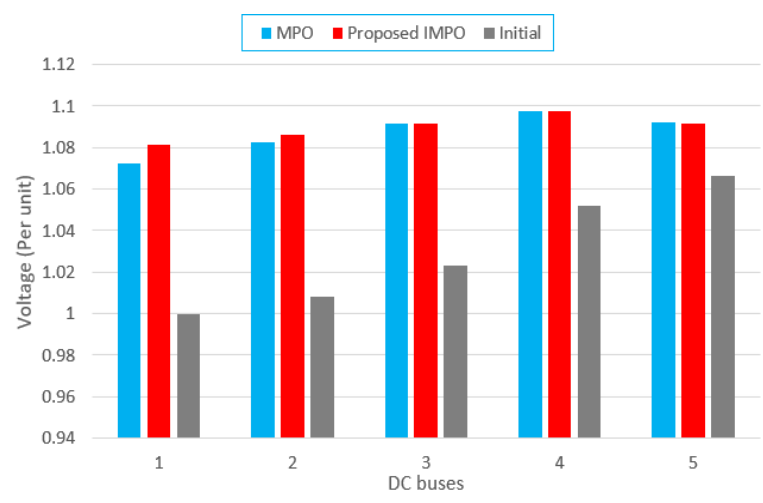

Figure 4. Voltages of HVDC grid for fuel cost minimization
High capability in finding the minimum considered objective function and progress through the iterations to evolutionarily search for the optimal solution of the proposed IMPO is particularly illustrated in Figure 5.

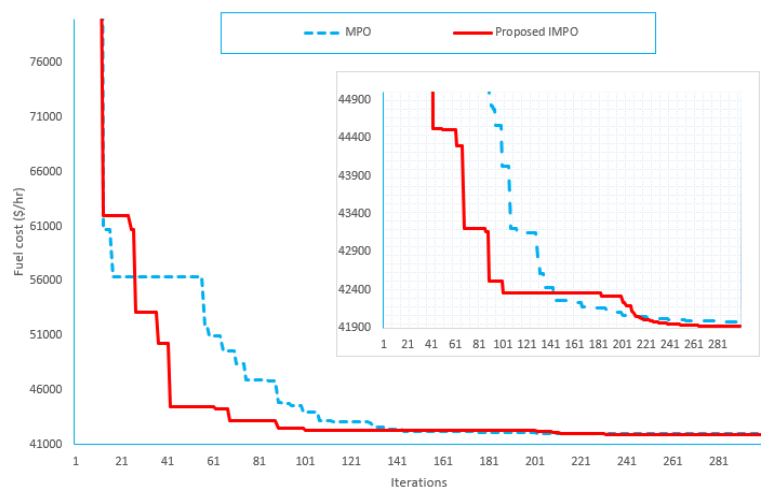

Figure 5. Convergence curve of IMPO and MPO (Case 1)

\section{Case 2: Power Losses Minimization}

In the second case, the power losses are considered as the primary objective function. The proposed technique achieves the lowest power losses, and it is superior to the techniques listed in Table 2. The total power losses are reduced by $69.06 \%$ using IMPO while its reduction level is achieved by $38.53 \%, 66.69 \%, 38.08 \%, 26.04 \%, 56.09 \%$, $64.19 \%$ and 68.86 using the GWO, PSO, SSA, MVO, DA, CSOA, BAT and conventional MPO, respectively. Figure 6 shows the voltage profile of AC grid for the initial case, MPO and IMPO. From this figure, the lowest voltage is $94.3 \%$ at bus 34 and $92.2 \%$ at bus 20 based on MPO and IMPO, respectively, whereas the highest voltage is $109.2 \%$ at bus 25 and $105.6 \%$ at bus 51 based on MPO and IMPO, respectively. This figure states the achievement of the voltage constraints whereas the voltages of all buses are within the allowable limits.

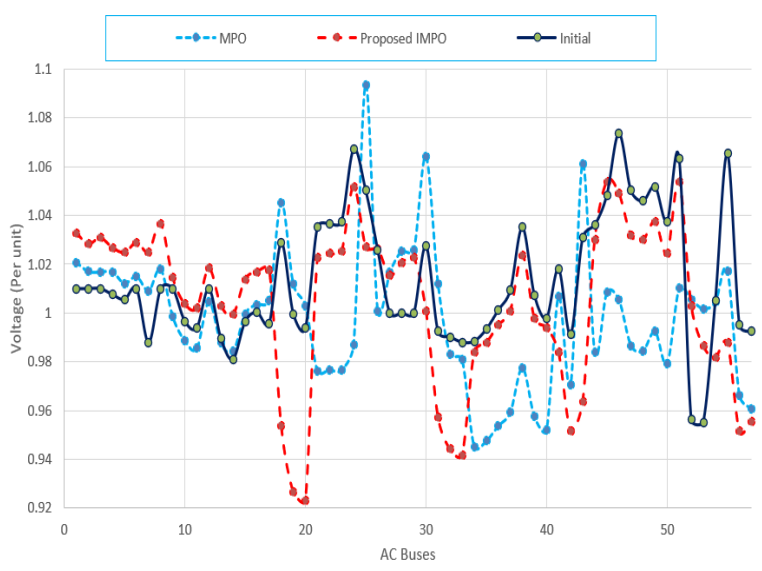

Figure 6. AC Voltages of IEEE 57-bus electrical grid 
Table 1. Optimal management of AC/DC 57-bus system of case 1

\begin{tabular}{|c|c|c|c|c|c|c|c|c|c|}
\hline & Initial & PSO & GWO & SSA & MVO & CSOA & DA & MPO & $\begin{array}{c}\text { Proposed } \\
\text { IMPO }\end{array}$ \\
\hline $\mathrm{Vg}_{1}$ & 1.01 & 1.002354 & 0.989824 & 1.042803 & 1.009714 & 0.99725 & 1.039031 & 0.969808 & 1.031114 \\
\hline $\mathrm{Vg}_{2}$ & 1.01 & 1.001094 & 0.984295 & 1.034984 & 0.994466 & 0.990963 & 1.023984 & 0.967658 & 1.031182 \\
\hline $\mathrm{Vg}_{3}$ & 1.01 & 1.000314 & 0.988379 & 1.024448 & 0.97643 & 0.990418 & 1.023181 & 0.963718 & 1.030151 \\
\hline $\mathrm{Vg}_{6}$ & 1.01 & 1.006917 & 0.991812 & 1.014798 & 0.975162 & 0.997543 & 1.025292 & 0.975249 & 1.044118 \\
\hline $\mathrm{Vg}_{8}$ & 1.01 & 1.010838 & 1.004194 & 1.026525 & 0.970011 & 1.012016 & 1.031709 & 0.993622 & 1.059188 \\
\hline $\mathrm{Vg}_{9}$ & 1.01 & 0.985069 & 0.991048 & 1.00815 & 0.965022 & 0.99128 & 0.997353 & 0.963055 & 1.028053 \\
\hline $\mathrm{Vg}_{12}$ & 1.01 & 0.989017 & 1.018258 & 1.021486 & 1.000024 & 1.010394 & 0.990036 & 0.956526 & 1.021772 \\
\hline $\operatorname{Tap}_{4-18}$ & 0.97 & 1.021519 & 0.924176 & 0.976689 & 1.09731 & 0.923581 & 0.953115 & 1.004439 & 0.960489 \\
\hline $\operatorname{Tap}_{4-18}$ & 0.978 & 1.036929 & 1.010297 & 1.01608 & 1.012529 & 1.029882 & 1.059182 & 0.955078 & 1.087195 \\
\hline $\operatorname{Tap}_{21-20}$ & 1.043 & 0.994797 & 0.910143 & 1.002725 & 0.940201 & 0.993682 & 1.020308 & 1.049319 & 1.025933 \\
\hline Tap $_{24-25}$ & 1 & 1.01696 & 0.909761 & 0.974383 & 1.013271 & 1.014796 & 0.943389 & 0.931082 & 0.957428 \\
\hline Tap $_{24-25}$ & 1 & 1.013014 & 1.05493 & 0.99662 & 0.900606 & 1.012827 & 0.926249 & 1.063228 & 0.979183 \\
\hline $\operatorname{Tap}_{24-26}$ & 1.043 & 1.048825 & 1.030452 & 1.003804 & 1.099391 & 1.012414 & 1.082859 & 1.053437 & 1.037316 \\
\hline Tap $_{7-29}$ & 0.967 & 1.010386 & 0.947328 & 0.984921 & 0.943102 & 1.009483 & 1.015269 & 1.003123 & 1.042982 \\
\hline Tap $_{34-32}$ & 0.975 & 0.941346 & 0.949934 & 1.012413 & 1.03216 & 0.977614 & 0.928913 & 1.009717 & 1.001312 \\
\hline Tap $_{11-41}$ & 0.955 & 0.902944 & 1.045508 & 1.018169 & 0.91687 & 0.936444 & 1.030718 & 0.954785 & 0.930065 \\
\hline Tap $_{15-45}$ & 0.955 & 0.98418 & 0.923845 & 1.02038 & 1.012515 & 0.992229 & 0.971784 & 0.955408 & 0.993982 \\
\hline Tap $_{14-46}$ & 0.9 & 0.96316 & 1.07511 & 0.971932 & 0.939397 & 0.989475 & 0.980909 & 0.944868 & 1.000395 \\
\hline $\operatorname{Tap}_{10-51}$ & 0.93 & 0.969336 & 0.978229 & 0.993918 & 0.916039 & 0.995085 & 1.016275 & 0.940231 & 0.996062 \\
\hline Tap $_{13-49}$ & 0.895 & 0.912633 & 0.97385 & 0.953083 & 1.027398 & 1.044325 & 1.050336 & 0.915011 & 0.951528 \\
\hline Tap $_{11-43}$ & 0.958 & 0.996662 & 0.930892 & 0.989476 & 0.907999 & 0.998629 & 0.990923 & 0.902361 & 1.026796 \\
\hline Tap $_{40-56}$ & 0.958 & 0.970352 & 0.968763 & 0.967216 & 0.952426 & 0.985333 & 0.968055 & 0.969713 & 0.993975 \\
\hline $\operatorname{Tap}_{39-57}$ & 0.98 & 1.010658 & 0.946883 & 0.999368 & 0.925374 & 1.009356 & 0.941237 & 0.948158 & 1.061182 \\
\hline Tap $_{9-55}$ & 0.94 & 1.002123 & 1.054834 & 1.006757 & 1.031598 & 0.970933 & 1.052346 & 1.028878 & 1.022776 \\
\hline $\mathrm{Qc}_{18}$ & 10 & 20.82041 & 4.312296 & 3.581033 & 12.95747 & 14.2749 & 6.696651 & 4.7E-05 & 13.77331 \\
\hline $\mathrm{Qc}_{25}$ & 5.9 & 22.80891 & 1.738346 & 11.70977 & 4.435347 & 16.44474 & 4.399598 & 18.67582 & 4.847247 \\
\hline $\mathrm{Qc}_{53}$ & 6.3 & 12.69323 & 11.11283 & 25.21283 & 22.655 & 13.1257 & 8.003974 & 24.64655 & 0.071487 \\
\hline $\mathrm{Pg}_{1}$ & 502.8454 & 142.6684 & 139.8862 & 317.7461 & 176.6879 & 150.7493 & 216.6632 & 142.5726 & 140.569 \\
\hline $\mathrm{Pg}_{2}$ & 0 & 89.09314 & 51.02812 & 33.61253 & 9.788236 & 66.24277 & 62.60842 & 84.80496 & 95.33554 \\
\hline $\mathrm{Pg}_{3}$ & 40 & 46.26461 & 113.7406 & 69.28428 & 1.721696 & 49.94074 & 44.43256 & 51.48741 & 49.50249 \\
\hline $\mathrm{Pg}_{6}$ & 0 & 91.68109 & 65.94795 & 48.98185 & 77.99036 & 57.36124 & 80.53949 & 60.06024 & 84.22161 \\
\hline $\mathrm{Pg}_{8}$ & 450 & 452.7275 & 453.399 & 396.0384 & 526.9059 & 491.0271 & 508.427 & 469.469 & 457.6436 \\
\hline $\mathrm{Pg}_{9}$ & 0 & 86.31989 & 68.48959 & 47.43804 & 99.68592 & 84.41735 & 41.36505 & 99.97297 & 87.1126 \\
\hline $\mathrm{Pg}_{12}$ & 310 & 362.9624 & 388.2114 & 359.3572 & 402.3648 & 374.2347 & 327.8484 & 364.5588 & 357.2527 \\
\hline $\mathrm{Qs}_{1}$ & 17.31 & -3.57276 & 9.079006 & 5.242268 & 26.61384 & 8.973198 & 48.68056 & 5.07619 & 39.0992 \\
\hline $\mathrm{Vc}_{2}$ & 1 & 0.962488 & 1.065763 & 1.023551 & 1.031025 & 0.982374 & 1.013627 & 0.949033 & 0.997751 \\
\hline $\mathrm{Vc}_{3}$ & 1 & 0.984194 & 1.026463 & 1.019515 & 1.03593 & 1.007273 & 0.976826 & 0.952505 & 1.005952 \\
\hline $\mathrm{Vc}_{4}$ & 1 & 0.996876 & 1.042444 & 1.028911 & 1.054962 & 1.007466 & 1.011353 & 0.96394 & 1.011372 \\
\hline $\mathrm{Vc}_{5}$ & 1 & 0.982782 & 0.973354 & 1.010234 & 0.94788 & 1.019458 & 0.942847 & 0.957171 & 1.011513 \\
\hline $\mathrm{Ps}_{2}$ & 25.47 & -3.93079 & 1.045948 & 24.45038 & 61.47052 & -1.67713 & 17.00733 & -3.84927 & -2.10468 \\
\hline $\mathrm{Ps}_{3}$ & 52.53 & -0.85298 & -51.9716 & -22.3203 & -57.7112 & 5.425147 & -48.9647 & -16.6255 & 3.545111 \\
\hline $\mathrm{Ps}_{4}$ & -59.91 & -33.5294 & -25.3033 & -27.8472 & 34.89706 & -33.978 & 16.77137 & -49.1198 & -53.1206 \\
\hline $\mathrm{Ps}_{5}$ & -59.91 & 9.201178 & -11.2341 & 8.390002 & -67.8524 & 9.392976 & 10.99611 & 22.34716 & 24.7504 \\
\hline $\mathrm{V}_{\mathrm{dc}, 1}$ & 1 & 1.07147 & 0.971244 & 1.00117 & 0.925581 & 0.95129 & 0.910742 & 1.072334 & 1.081167 \\
\hline $\mathrm{F}_{1}$ & $\mathbf{5 3 6 7 3 . 1 5 5 5}$ & 41932.79 & 43621.92 & 44791.52 & 43628.05 & 42050.22 & 42796.13 & 41987.91 & 41920.67 \\
\hline $\mathrm{F}_{3}$ & 52.044 & 20.91701 & 29.9029 & 21.65838 & 44.34475 & 23.17326 & 31.08415 & 22.12592 & 20.83751 \\
\hline
\end{tabular}


Table 2. Optimal management of AC/DC 57-bus system for case 2

\begin{tabular}{|c|c|c|c|c|c|c|c|c|c|}
\hline & Initial & PSO & GWO & SSA & MVO & CSOA & DA & MPO & $\begin{array}{c}\text { Proposed } \\
\text { IMPO }\end{array}$ \\
\hline $\mathrm{Vg}_{1}$ & 1.01 & 1.013528 & 0.98752 & 1.054032 & 1.00402 & 1.017326 & 1.017621 & 1.020786 & 1.032772 \\
\hline $\mathrm{Vg}_{2}$ & 1.01 & 1.007629 & 0.982916 & 1.047983 & 0.999808 & 1.011667 & 1.001235 & 1.016958 & 1.028292 \\
\hline $\mathrm{Vg}_{3}$ & 1.01 & 1.019935 & 0.992293 & 1.036569 & 1.016112 & 1.004438 & 1.009508 & 1.016788 & 1.030832 \\
\hline $\mathrm{Vg}_{6}$ & 1.01 & 1.028045 & 1.015404 & 1.036507 & 1.048556 & 0.992195 & 1.034138 & 1.014975 & 1.02887 \\
\hline $\mathrm{Vg}_{8}$ & 1.01 & 1.033236 & \begin{tabular}{|l|}
1.055377 \\
\end{tabular} & \begin{tabular}{|l|}
1.056848 \\
\end{tabular} & 1.059435 & \begin{tabular}{|l|}
0.986282 \\
\end{tabular} & \begin{tabular}{|l|}
1.034012 \\
\end{tabular} & 1.017991 & 1.036743 \\
\hline $\mathrm{Vg}_{9}$ & 1.01 & 1.001119 & 1.006774 & 1.021916 & 0.997904 & 0.981611 & 1.003072 & 0.9985 & 1.014371 \\
\hline $\mathrm{Vg}_{12}$ & 1.01 & 0.995993 & 0.992424 & 1.018467 & 0.941723 & 1.017655 & 0.996969 & 1.004611 & 1.018322 \\
\hline Tap $_{4-18}$ & 0.97 & 0.989465 & 0.973761 & 1.027283 & 0.903315 & 1.003031 & 0.988053 & 1.019925 & 1.020221 \\
\hline Tap $_{4-18}$ & 0.978 & 1.03168 & \begin{tabular}{|l|}
0.952705 \\
\end{tabular} & \begin{tabular}{|l|}
0.995436 \\
\end{tabular} & \begin{tabular}{|l|}
1.094193 \\
\end{tabular} & \begin{tabular}{|l|}
0.989393 \\
\end{tabular} & \begin{tabular}{|l|}
0.959611 \\
\end{tabular} & \begin{tabular}{|l|}
0.984839 \\
\end{tabular} & 1.098514 \\
\hline Tap $_{1-20}$ & 1.043 & 1.034672 & 1.010028 & 1.027 & 0.903458 & 0.978811 & 0.931846 & 0.972598 & 1.09822 \\
\hline $\operatorname{Tap}_{4-25}$ & 1 & 0.976685 & 0.983516 & 0.994851 & 1.09488 & 0.97778 & \begin{tabular}{|l|}
0.989616 \\
\end{tabular} & 1.003449 & 0.954546 \\
\hline $\operatorname{Tap}_{4-25}$ & 1 & 1.001464 & 1.002386 & 1.005231 & 0.929633 & 1.055273 & 1.021871 & 1.018675 & 1.041171 \\
\hline Tap $_{4-26}$ & 1.043 & 1.002888 & 1.010628 & 1.009663 & 0.934696 & \begin{tabular}{|l|}
0.953215 \\
\end{tabular} & 1.020882 & 0.977776 & 1.031687 \\
\hline Tap $_{7-29}$ & 0.967 & 1.041659 & 0.936146 & 1.02505 & 1.077697 & 0.994077 & 1.017556 & 0.982502 & 0.999846 \\
\hline Tap $_{4-32}$ & 0.975 & 1.012741 & 0.939759 & 0.971312 & 0.916635 & \begin{tabular}{|l|}
0.975998 \\
\end{tabular} & 1.021777 & 0.968896 & 1.03305 \\
\hline Tap $_{1-41}$ & 0.955 & 0.99451 & 1.003855 & \begin{tabular}{|l|}
0.972884 \\
\end{tabular} & 1.1 & \begin{tabular}{|l|}
1.026297 \\
\end{tabular} & \begin{tabular}{|l|}
0.994423 \\
\end{tabular} & 1.012657 & 0.933187 \\
\hline Tap $_{5-45}$ & 0.955 & 0.950309 & 1.024767 & 1.013423 & 0.917551 & 0.982312 & 1.014348 & 0.985959 & 0.957835 \\
\hline Tap $_{4-46}$ & 0.9 & 0.960829 & \begin{tabular}{|l|}
0.948044 \\
\end{tabular} & \begin{tabular}{|l|}
0.982832 \\
\end{tabular} & 0.92204 & 1.00035 & 1.002595 & 0.967915 & 0.944039 \\
\hline Tap $_{0-51}$ & 0.93 & 1.003188 & 0.950723 & \begin{tabular}{|l|}
0.990196 \\
\end{tabular} & 0.916125 & \begin{tabular}{|l|}
1.005042 \\
\end{tabular} & 1.007994 & 0.97168 & 0.945852 \\
\hline Tap $_{3-49}$ & 0.895 & 0.962515 & 0.969769 & 1.007868 & 1.084644 & 0.986865 & 0.993832 & 0.948679 & 0.926106 \\
\hline Tap $_{1-43}$ & 0.958 & 0.949731 & 1.016348 & 0.978676 & 0.9 & 0.941204 & \begin{tabular}{|l|}
0.994166 \\
\end{tabular} & 0.909366 & 1.045187 \\
\hline Tap $_{0-56}$ & 0.958 & 1.054972 & 0.964294 & \begin{tabular}{|l|}
0.964839 \\
\end{tabular} & 0.9 & \begin{tabular}{|l|}
1.000846 \\
\end{tabular} & 1.03941 & 0.96446 & 1.037867 \\
\hline Tap $_{9-57}$ & 0.98 & 0.993118 & 0.983341 & 0.976236 & 0.916752 & 1.003722 & 1.006346 & 0.960195 & 0.966309 \\
\hline Tap $_{9-55}$ & 0.94 & 1.033759 & 0.960833 & 0.99308 & 1.097116 & 0.969157 & 0.989685 & 0.979883 & 1.026 \\
\hline $\mathrm{Qc}_{18}$ & 10 & 18.00064 & 0.858942 & 11.88416 & 29.91103 & \begin{tabular}{|l|l|}
19.10894 \\
\end{tabular} & 6.621916 & 22.80821 & 7.77114 \\
\hline $\mathrm{Qc}_{25}$ & 5.9 & 10.42872 & 19.41944 & 18.10625 & 18.36218 & 14.48901 & 10.18445 & 28.73526 & 5.827695 \\
\hline $\mathrm{Qc}_{53}$ & 6.3 & 15.50351 & 14.24023 & 18.55558 & 9.000708 & 11.69681 & 17.86088 & 20.99919 & 11.5213 \\
\hline $\mathrm{Pg}_{1}$ & 502.8454 & 187.6162 & 258.7036 & 358.1133 & 282.0413 & 178.486 & 182.4158 & 158.297 & 177.6463 \\
\hline $\mathrm{Pg}_{2}$ & 0 & 26.5678 & 49.4776 & 57.66969 & 40.31349 & 59.84177 & 73.34906 & 45.71808 & 26.32417 \\
\hline $\mathrm{Pg}_{3}$ & 40 & 124.7837 & 47.24564 & 88.64899 & 90.22706 & 105.9616 & 64.42822 & 107.001 & 134.129 \\
\hline $\mathrm{Pg}_{6}$ & 0 & 55.11864 & 60.13427 & 26.28787 & 53.7489 & 59.90465 & 59.30094 & 99.84966 & 92.18518 \\
\hline $\mathrm{Pg}_{8}$ & 450 & 380.051 & 506.5693 & 468.2737 & 481.3725 & 380.9615 & 423.9701 & 346.2212 & 355.7217 \\
\hline $\mathrm{Pg}_{9}$ & 0 & 86 & 38.21112 & 26.91557 & 21.3477 & \begin{tabular}{|l|}
75.65044 \\
\end{tabular} & \begin{tabular}{|l|}
60.19788 \\
\end{tabular} & 99.92209 & 70.89514 \\
\hline $\mathrm{Pg}_{12}$ & 310 & 408 & 322.448 & 257.1158 & 320.2414 & 408.6291 & 409.991 & 409.9996 & 409.9999 \\
\hline $\mathrm{Qs}_{1}$ & 17.31 & 6.459733 & 22.50295 & 22.33157 & 39.56363 & 10.57488 & 30.69999 & -20.2437 & 21.83724 \\
\hline $\mathrm{Vc}_{2}$ & 1 & 0.973916 & 1.006852 & 0.995423 & 1.066251 & 1.02593 & 1.03065 & 1.016599 & 1.015466 \\
\hline $\mathrm{Vc}_{3}$ & 1 & 0.993909 & 1.03823 & 1.008114 & 1.027548 & 1.021979 & 1.030684 & 1.025402 & 1.020485 \\
\hline $\mathrm{Vc}_{4}$ & 1 & 0.998391 & 1.049397 & 1.024482 & 1.031273 & 1.016028 & \begin{tabular}{|l|}
1.041099 \\
\end{tabular} & 1.025772 & 1.022565 \\
\hline $\mathrm{Vc}_{5}$ & 1 & 0.98584 & 1.060185 & 0.991878 & 1.077522 & \begin{tabular}{|l|}
0.997033 \\
\end{tabular} & 1.031965 & 1.005511 & 1.002952 \\
\hline $\mathrm{Ps}_{2}$ & 25.47 & -1.38876 & 2.573905 & 14.98112 & -18.6915 & 12.2878 & -17.5081 & -2.79867 & 4.453797 \\
\hline $\mathrm{Ps}_{3}$ & 52.53 & 8.685172 & 33.91094 & -11.3981 & -0.11158 & -18.9883 & -39.4296 & 19.37672 & 6.419814 \\
\hline $\mathrm{Ps}_{4}$ & -59.91 & -48.3455 & -62.8475 & 19.74161 & -50.9951 & -27.811 & \begin{tabular}{|l|}
8.818256 \\
\end{tabular} & -47.12 & -44.9283 \\
\hline $\mathrm{Ps}_{5}$ & -59.91 & 18.68169 & 47.08576 & \begin{tabular}{|l|}
-13.9763 \\
\end{tabular} & 69.02862 & 12.73654 & 1.327176 & 8.130772 & 13.19037 \\
\hline $\mathrm{V}_{\mathrm{dc}, 1}$ & 1 & 1.068932 & 0.97931 & 0.981125 & 1.1 & 1.023502 & 1.012039 & 1.083256 & 1.084052 \\
\hline $\mathrm{F}_{1}$ & 53673.1555 & 44030.97 & 43494.19 & 46844.65 & 44807.75 & 43315.53 & \begin{tabular}{|l|}
42491.27 \\
\end{tabular} & 43363.03 & 44448.74 \\
\hline Plosses AC & 40.644 & 11.14112 & 24.87687 & 26.40071 & 31.14361 & 12.53118 & 16.42155 & 9.991226 & 9.972723 \\
\hline $\begin{array}{l}\text { Plosses } \\
\text { VSC }\end{array}$ & 6.3 & 5.810581 & 6.07089 & 5.707222 & 6.004269 & 5.722191 & 5.789848 & 5.789498 & 5.741743 \\
\hline Plosses DC & 5.1 & 0.385716 & 1.04174 & \begin{tabular}{|l|}
0.116966 \\
\end{tabular} & 1.344526 & \begin{tabular}{|l|}
0.381657 \\
\end{tabular} & \begin{tabular}{|l|}
0.641645 \\
\end{tabular} & 0.427864 & 0.386856 \\
\hline $\mathrm{F}_{3}$ & 52.044 & 17.33742 & 31.9895 & 32.2249 & 38.4924 & 18.63502 & 22.85304 & 16.20859 & 16.10132 \\
\hline
\end{tabular}


Figure 7 shows the convergence curve related to IMPO and MPO for Case 2. This graph shows the high convergence rates correlated with the ability of the IMPO to find the optimum solution.

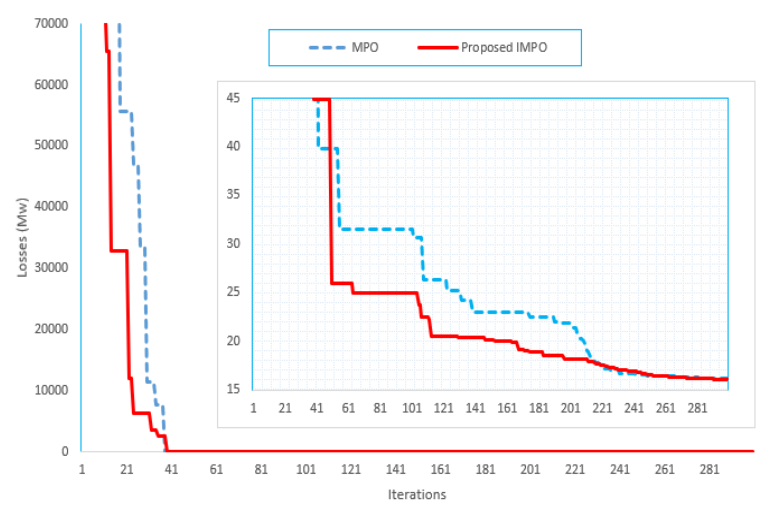

Figure 7. Convergence curve of IMPO and MPO (Case 2)

\section{Case 3: Multi-objective of Simultaneous Minimization of Fuel Costs and Losses}

The Pareto set solutions for optimal operation of AC/MTHVDC with bi-objective functions, fuel costs and power losses minimization, are handled by the IMPO and illustrated in Figure 8. Fuel costs are minimized from $42820(\$ / \mathrm{hr})$ to $42600(\$ / \mathrm{hr})$, whereas the losses are increased inversely with fuel cost minimization whose value changes from $16 \mathrm{MW}$ to $17.17 \mathrm{MW}$.

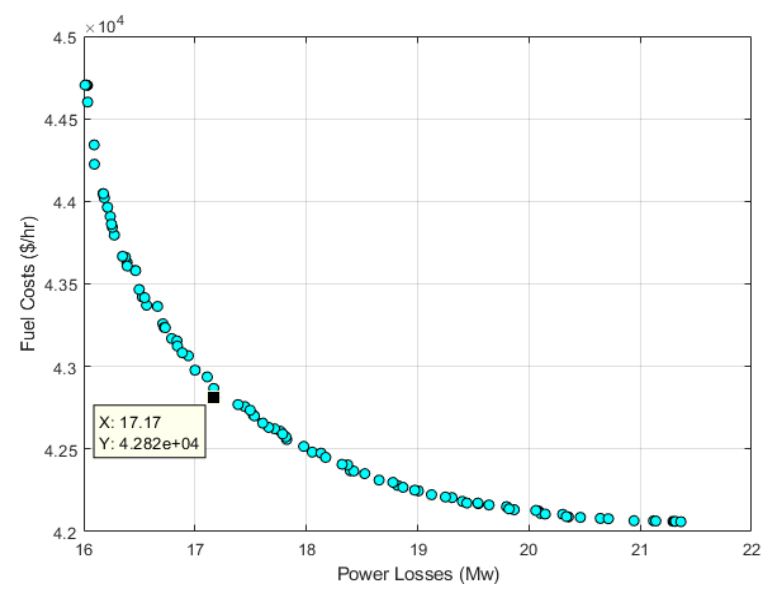

Figure 8. Pareto solutions for Case 3

\section{Robustness Analysis}

To perform the robustness analysis, the obtained minimum fuel costs of the compared algorithms are recorded. Their spread and centres are displayed in Figure 9 via Box and Whiskers plot.
The proposed algorithm provides better robustness statistics in comparison with the others. It provides the smallest maximum, average and minimum values of 41920.67, 41979.2 and 42052.12 \$/hr with smallest standard deviation.

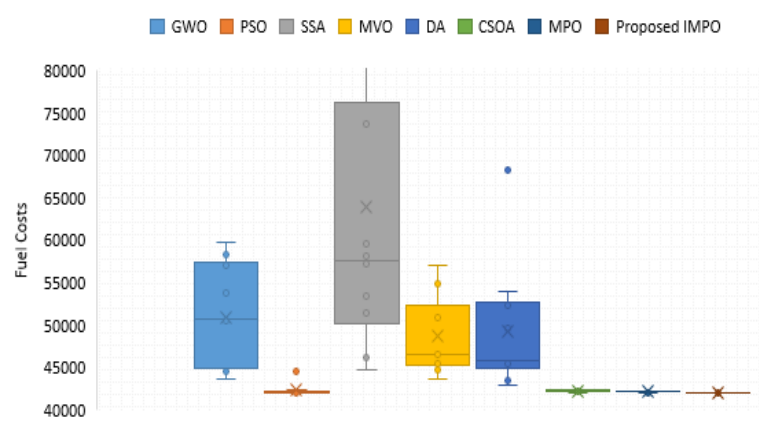

Figure 9. Box and Whiskers plot for Case 1

For this real application on the AC/DC 57bus system, Table 3 summarizes the reduction advantages in technical and economic terms of the proposed methodology. Economically, the proposed IMPO can minimize the total fuel cost with reductions of $21.89 \%, 17.18 \%$ and $20.22 \%$ for all the three analyzed cases. Technically, the proposed IMPO can minimize the total power losses with reductions of $59.96 \%, 69.06 \%$ and $67 \%$ for all analyzed cases.

Table 3. Reduction advantages in technical and economic terms of the proposed methodology of AC/DC 57-bus system

\begin{tabular}{|c|c|c|c|c|}
\hline & Initial & Case 1 & Case 2 & Case 3 \\
\hline Economic $\mathrm{F}_{1}$ & 53673.15 & 41920.67 & 44448.74 & 42820 \\
\hline Reduction \% & - & $21.89 \%$ & $17.18 \%$ & $20.22 \%$ \\
\hline Technical $\mathrm{F}_{3}$ & 52.044 & 20.83751 & 16.10132 & 17.17 \\
\hline Reduction \% & - & $59.96 \%$ & $69.06 \%$ & $67 \%$ \\
\hline
\end{tabular}

\section{Conclusion}

This article presented the improved version of Marine Predators Optimizer for finding the optimal technical and economic operation of hybrid AC and MTHVDC grids. To achieve the economic, technical, and environmental benefits of the generation units, the multi-objective formulation of hybrid grid optimal operation is considered. However, the proposed method has well-diversified Pareto solutions, whilst a compromise operational solution is successfully deduced so as to meet the needs of the operator. 
The proposed IMPO has been applied and verified on three analyzed cases. The analyzed cases have been investigated for the modified IEEE 57-bus that is represented through $\mathrm{AC} / \mathrm{DC}$ grid. The emulated results reveal the preponderance and efficacy of the proposed algorithm with great stability indices over other competitive algorithms in literature for single and multi-objective cases.

\section{Nomenclature}

$\mathrm{Pg}_{\mathrm{i}}$ : output active power in MW of generator $\mathrm{i}$ $a_{i}, b_{i}$, and $c_{i}$ : the generators' cost coefficients

$\mathrm{Ng}$ : the number of generators

$\mathrm{AC}_{\text {loss }}: \mathrm{AC}$ grid line losses

$\mathrm{DC}_{\text {loss }}$ : DC transmission losses

VSC $_{\text {loss }}:$ VSC stations loss

$\mathrm{Ic}_{\mathrm{i}}$ : converter current

$\varphi_{1}, \varphi_{2}$, and $\varphi_{3}$ : the loss coefficients

$\mathrm{N}_{\mathrm{AC}, \mathrm{b}}$ and $\mathrm{N}_{\mathrm{DC}, \mathrm{b}}$ : the number of AC and DC buses

NPQ : the number of load buses

$\mathrm{NF}$ : the number of transmission lines

\section{REFERENCES}

Donde, V., Feng, X., Member, S. \& Segerqvist, I. (2016). Distributed State Estimation of Hybrid AC/ HVDC Grids by Network Decomposition, IEEE Transactions on Smart Grid, 7(2), 974-981.

Duan, J., Zeng, W. \& Chow, M. (2018). Resilient Distributed DC Optimal Power Flow Against Data Integrity Attack, IEEE Transactions on Smart Grid, 9(4), 3543-3552.

Elsayed, A. M., Shaheen, A. M., Alharthi, M. M., Ghoneim, S. M. \& El-Sehiemy, R. A. (2021). Adequate Operation of Hybrid AC/MT-HVDC Power Systems Using an Improved Multi- Objective Marine Predators Optimizer, IEEE Access, 9, 51065-51087.

El-Sehiemy, R. A., El-Hosseini, M. A. \& Hassanien, A. E. (2013). Multiobjective Real-Coded Genetic Algorithm for Economic / Environmental Dispatch Problem, Studies in Informatics and Control, 22(2), 113-122. DOI: 10.24846/v22i2y201301

Enache, A.-C., Sgarciu, V. \& Petrescu-Nita, A. (2015). Intelligent feature selection method rooted in Binary Bat Algorithm for intrusion detection. In 2015 IEEE 10th Jubilee International Symposium on Applied Computational Intelligence and Informatics, (pp. 517 521). DOI: 10.1109/SACI.2015.7208259

Faramarzi, A., Heidarinejad, M., Mirjalili, S. \& Gandomi, A. H. (2020). Marine predators algorithm: A nature-inspired Metaheuristic, Expert Systems with Applications, 152. Art. no. 113377.
$\mathrm{N}_{\mathrm{b}}$ : the number of buses

$\mathrm{PL}_{\mathrm{i}}$ and $\mathrm{QL}_{\mathrm{i}}$ : active and reactive demand at bus $\mathrm{i}$ $\mathrm{G}_{\mathrm{ij}}$ and $\mathrm{B}_{\mathrm{ij}}$ : mutual conductance and mutual susceptance among bus $\mathrm{i}$ and $\mathrm{j}$, respectively

$\mathrm{P}_{\mathrm{dc}, \mathrm{i}}$ : the injected power at bus $\mathrm{i}$

$\mathrm{P}_{\text {Size }}^{\mathrm{dc}, \mathrm{i}}$ : population size

$\mathrm{E}$ : Elite matrix

$\mathrm{X}_{\mathrm{i}}$ : the current position for each prey (i)

$E_{i}$ : the position of the top predator (i) from the elite matrix

It and Maxit: the current iteration and its maximum number

$\mathrm{X}_{\max }$ and $\mathrm{X}_{\min }$ : the maximum and minimum vectors $\mathrm{U}$ displays a random binary vector

\section{Acknowledgements}

The authors would like to acknowledge the financial support received from Taif University Researchers Supporting Project Number (TURSP-2020/122), Taif University, Taif, Saudi Arabia.

Hamad, A. A. \& El-Saadany, E. F. (2016). Multi-agent supervisory control for optimal economic dispatch in DC microgrids, Sustainable Cities and SoCiety, 27, 129-136.

Hotz, M. \& Utschick, W. (2020). hynet : An Optimal Power Flow Framework for Hybrid AC / DC Power Systems, IEEE Transactions on Power Systems, 35(2), 1036-1047.

Li, G., Wang, H., Bian, J., Yang, Y. \& Hu, J. (2019). Study of multi-objective optimal power flow of AC DC hybrid system with DCpower flow controller, The Journal of Engineering, 16, 1743-1749.

Li, J., Liu, F., Wang, Z., Low, S. \& Mei, S. (2018). Optimal Power Flow in Stand-Alone DC Microgrids, IEEE Transactions on Power Systems, 33(5), 54965506. DOI: 10.1109/TPWRS.2018.2801280

Mackay, L., Member, G. S. \& Guarnotta, R. (2018). Optimal Power Flow for Unbalanced Bipolar DC Distribution Grids, IEEE Access, 6, 5199-5207. DOI: 10.1109/ACCESS.2018.2789522

Maulik, A. \& Das, D. (2019). Optimal power dispatch considering load and renewable generation uncertainties in an AC - DC hybrid microgrid, IET Generation, Transmission \& Distribution, 13(7), 1164-1176. DOI: 10.1049/iet-gtd.2018.6502

Meng, X.-B., Gao, X. Z., Yu, L. \& Zhang, H. (2015). A novel bat algorithm with habitat selection and Doppler 
effect in echoes for optimization, Expert Systems with Applications, 42(17-18), 6350-6364. Available at $<$ http://dx.doi.org/10.1016/j.eswa.2015.04.026>.

Mirjalili, S. (2016). Dragonfly algorithm: a new metaheuristic optimization technique for solving singleobjective, discrete, and multi-objective problems, Neural Computing and Applications, 27(4), 10531073. DOI: 10.1007/s00521-015-1920-1

Mohagheghi, E., Alramlawi, M., Gabash, A. \& Li, P. (2018). A survey of real-time optimal power flow, Energies, 11(11), 3142. DOI: 10.3390/en11113142

Renedo, J., Asrul, A., Kazemtabrizi, B., GarcíaCerrada, A., Rouco, L., Zhao, Q. \& García-González, J. (2019). A simplified algorithm to solve optimal power flows in hybrid VSC-based AC / DC systems, Electrical Power \& Energy Systems, 110, 781-794.

Sau-Bassols, J., Zhao, Q., García-González, J., Prieto-Araujo, E. \& Gomis-Bellmunt, O. (2019). Optimal power flow operation of an interline current flow controller in an hybrid AC / DC meshed grid, Electric Power Systems Research, 177, 105935. DOI 10.1016/j.epsr.2019.105935

Sayah, S. (2018). Modified differential evolution approach for practical optimal reactive power dispatch of hybrid AC-DC power systems, Applied Soft Computing Journal, 73, 591-606. DOI: 10.1016/j. aSoC.2018.08.038

Secui, D. C., Bendea, G., Dzițac, S., Bendea, C. \& Hora, C. (2014). A modified harmony search algorithm for the economic dispatch problem, Studies in Informatics and Control, 23(2), 143-152. DOI: $10.24846 / \mathrm{v} 23 \mathrm{i} 2 \mathrm{y} 201402$

Shafik, M. B., Chen, H., Rashed, G. I. \& El-Sehiemy, R. A. (2019). Adaptive multi objective parallel seeker optimization algorithm for incorporating TCSC devices into optimal power flow framework, IEEE Access, 7, 36934-36947. DOI: 10.1109/ACCESS.2019.2905266

Shaheen, A. M. \& El-Sehiemy, R. A. (2017). Optimal allocation of capacitor devices on MV distribution networks using crow search algorithm, CIRED - Open Access Proceedings Journal, 2017(1), 2453-2457. DOI: 10.1049/oap-cired.2017.0020

Shaheen, A. M. \& El-Sehiemy, R. A. (2019). Application of multi-verse optimizer for transmission network expansion planning in power systems. In 2019 International Conference on Innovative Trends in Computer Engineering (ITCE), (pp. 371-376).
Shaheen, A. M., El-Sehiemy, R. A. \& Farrag, S. M. (2019). A reactive power planning procedure considering iterative identification of VAR candidate buses, Neural Computing and Applications, 31(3), 653-674. DOI: 10.1007/s00521-017-3098-1

Shaheen, A. M. \& El-Sehiemy, R. A. (2020a). A Multiobjective Salp Optimization Algorithm for Techno-Economic-Based Performance Enhancement ofDistribution Networks, IEEE Systems Journal, 15(1), 1458-1466. DOI: 10.1109/JSYST.2020.2964743

Shaheen, A. M. \& El-Sehiemy, R. A. (2020b). Optimal Co-ordinated Allocation of Distributed Generation Units/ Capacitor Banks/ Voltage Regulators by EGWA, IEEE Systems Journal, 15(1), 257-264. DOI: $10.1109 /$ jsyst.2020.2986647

Shaheen, A. M., El-Sehiemy, R. A., Elattar, E. E. \& Abd-Elrazek, A. (2021a). A Modified Crow Search Optimizer for Solving Non-Linear OPF Problem With Emissions, IEEE Access, 9, 43107-43120.

Shaheen, A. M., Elsayed, A. M., El-Sehiemy, R. A., Kamel, S. \& Ghoneim, S. S. M. (2021b). A modified marine predators optimization algorithm for simultaneous network reconfiguration and distributed generator allocation in distribution systems under differentloading conditions, Engineering Optimization, 1-22. DOI: 10.1080/0305215X.2021.1897799

Shaheen, A. M., El-Sehiemy, R. A., Elsayed, A. M. \& Elattar, E. E. (2021c). Multi-objective manta ray foraging algorithm for efficient operation of hybrid AC/DC power grids with emission minimisation, IET Generation, Transmission \& Distribution, 15(8), 1314-1336.

Warid, W. (2020). Optimal power flow using the AMTPG-Jaya algorithm, Applied Soft Computing Journal, 91, 106252. DOI: 10.1016/j. aSoC.2020.106252

Zhao, Q. \& Echavarren, M. (2017). Impact of Converter Losses on the Optimal Power Flow solution of Hybrid Networks based on VSC-MTDC, Electric Power Systems Research, 151, 395-403. 